\title{
PRELIMINARY VERIFICATION OF SELECTED SOLUTIONS FOR CRACK DETECTION
}

\author{
Artur Kurnyta \\ Piotr Reymer
}

Air Force Institute of Technology, Warsaw, Poland

\begin{abstract}
Throughout its service life an aircraft is subjected to varying loads. Because of those periodically appearing stresses, undesirable and irreversible changes in structure may occur. As a consequence, cracks are formed, which reduce aircraft structural strength, significantly affecting structural integrity. For that reason, intensive research works are carried out around the world to develop innovative and reliable methods for detection of cracks initiation and propagation. This paper presents two methods of crack detection. One of them uses wireless polymer gages for determining deformation in a test region. The other one uses electrical, resistive ladder sensors for detection of cracks and their length determination.
\end{abstract}

Keywords: Fatigue crack, crack detection, DMI SR2, polymer gage, ladder sensor.

\section{INTRODUCTION}

Currently, a big number of modern and innovative crack detection solutions are being developed. Unfortunately, there is lack of verified data from reliable, autonomous R\&D centers, confirming efficiency of those approaches. For that reason, special preliminary laboratory studies were conducted to verify the two selected measurement systems.

Laboratory tests on a fatigue-testing machine were performed to explore the reliability and sensitivity of the DMI SR2 optical system along with the resistive ladder sensors for crack detection. For this purpose appropriate specimens were prepared and examined under variable loads until a visible fatigue crack occurred.

\section{OPTICAL STRAIN MEASUREMENT USING POLYMER GAGES}

An initial verification of the DMI SR2 system was carried out. The system, which is an optical solution for determining deformation, also called direct strain measurement, is similar to the digital image correlation method. The captured images of a specified specimen area (in the unloaded and loaded state) are used to define the extent of deformation for a short line segment visible on the specimen's pattern. 

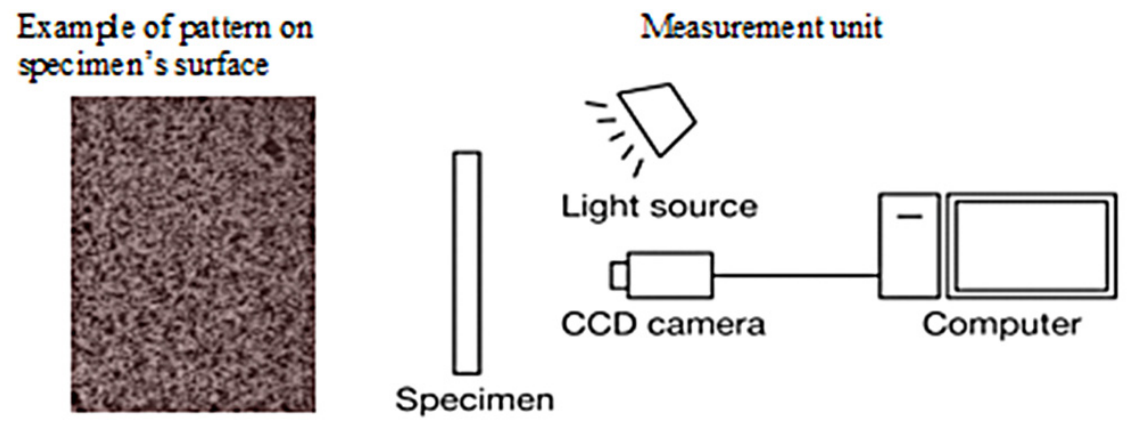

Figure 1. Components of optical strain measurement system

The DMI SR2 system utilizes a very unique pattern, which consists of a polymer gage permanently bonded to the specimen's surface. There is a precise geometrical pattern on each of the gages, which is used to determine strain, and also for self-identification purpose within the rest of the system. The gage is fitted to the structure using the same method that is used for foil strain gages. The view of the gage is shown in Figure 2.
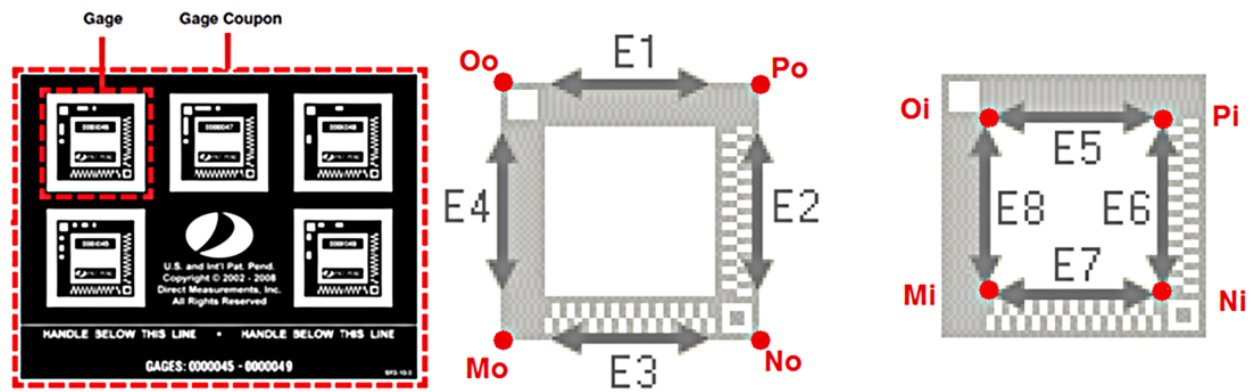

Figure 2. Polymer gage coupon and characteristic edges

The polymer gage has 8 characteristic nodes ( 4 inner - Mi, Ni, Oi, Pi, and 4 outer - Mo, No, Oo, Po), which gives 8 independent measurement line components. Gage deformation is determined separately for each line element, using a sensor with a digital camera connected to a PC equipped with dedicated software. By comparing strain values at different edges of the sensor (on the parallel, opposing line segments) it is possible to detect cracks and determine the direction of crack propagation.

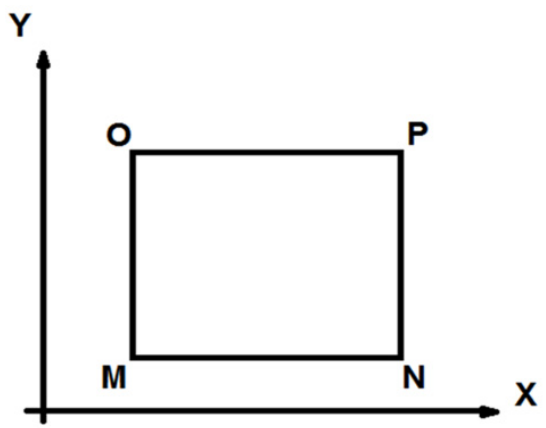

Element before deformation

$$
\begin{aligned}
& E_{M N}=\frac{\left|M^{\prime} N^{\prime}\right|-|M N|}{|M N|} \\
& E_{O P}=\frac{\left|O^{\prime} P^{\prime}\right|-|O P|}{|O P|}
\end{aligned}
$$

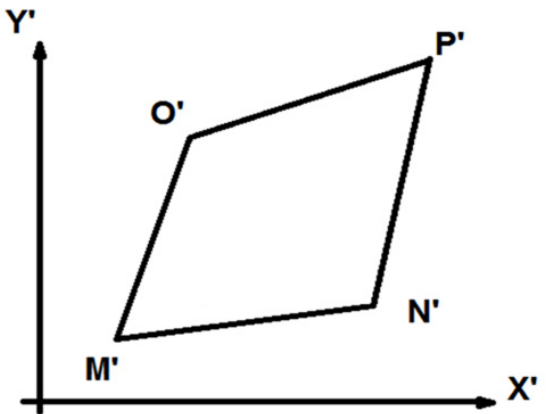

Element after deformation

$$
\begin{aligned}
E_{M O} & =\frac{\left|M^{\prime} O^{\prime}\right|-|M O|}{|M O|} \\
E_{N P} & =\frac{\left|N^{\prime} P^{\prime}\right|-|N P|}{|N P|}
\end{aligned}
$$

Figure 3. Non-uniform strain with equations 
The gage measures directly uniform (similarly to the $90^{\circ}$ rosette foil strain gage) or nonuniform deformations. Non-uniform or differential deformation of the opposing sides of the gage indicates non-uniform plastic strain (fatigue) or a crack. The software algorithm calculates strain in $\mu$ Str using equations in Figure 3.

\subsection{The conduct of testing and test results}

Preliminary tests were conducted on two types of specimens using a fatigue test system. The first one was a flat, rectangular specimen with a small, $3 \mathrm{~mm}$ fastener hole. The second specimen was a flat element with an "omega" type stiffener, interconnected with the rivet seam. Both specimens were made of PA7 aluminum, with dimensions H160xW50xT2 mm. The load was applied at a frequency of $10 \mathrm{~Hz}$. Measurements were conducted under two load values for each polymer gage. The results were illustrated in the graphs, separately for the inner and outer components of the gage.
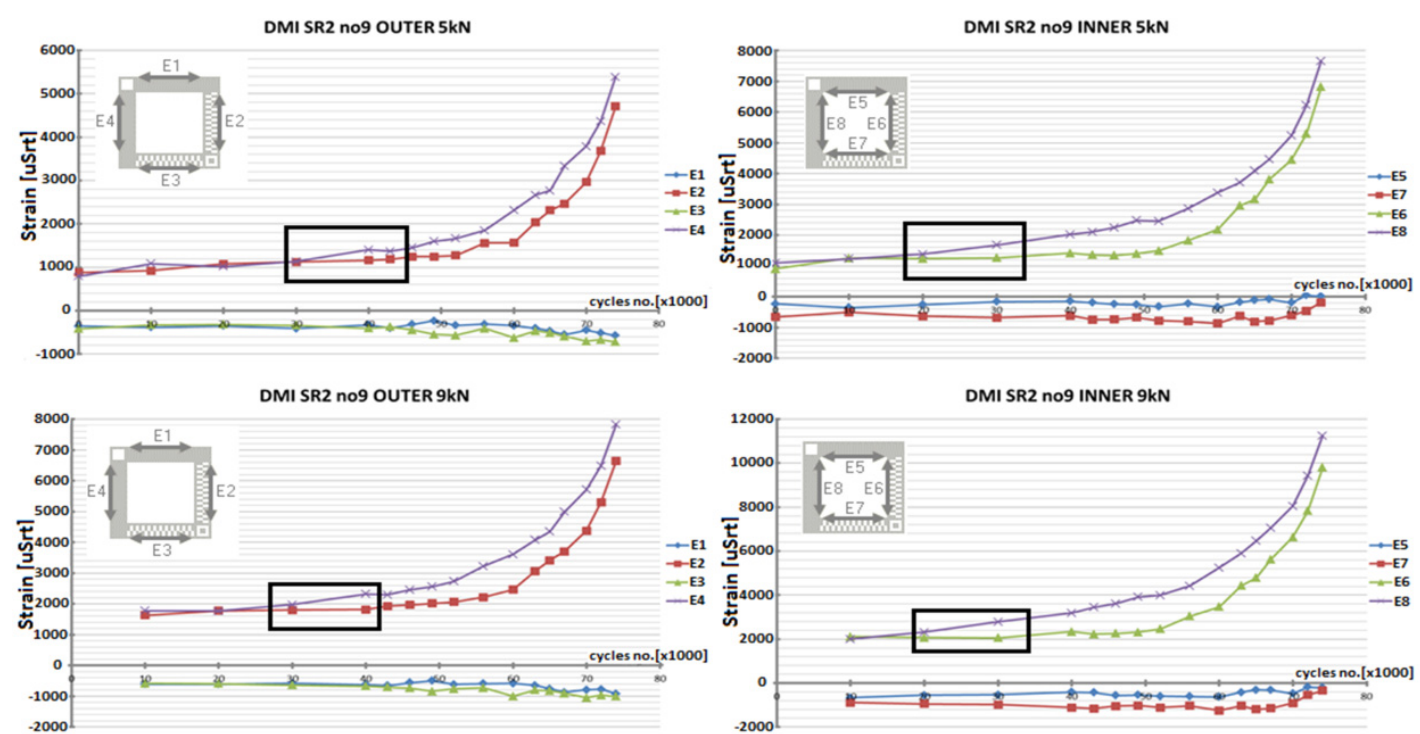

Figure 4. Test results for a flat specimen with a fastener hole under $5 \mathrm{kN}$ and $9 \mathrm{kN}$ axial load
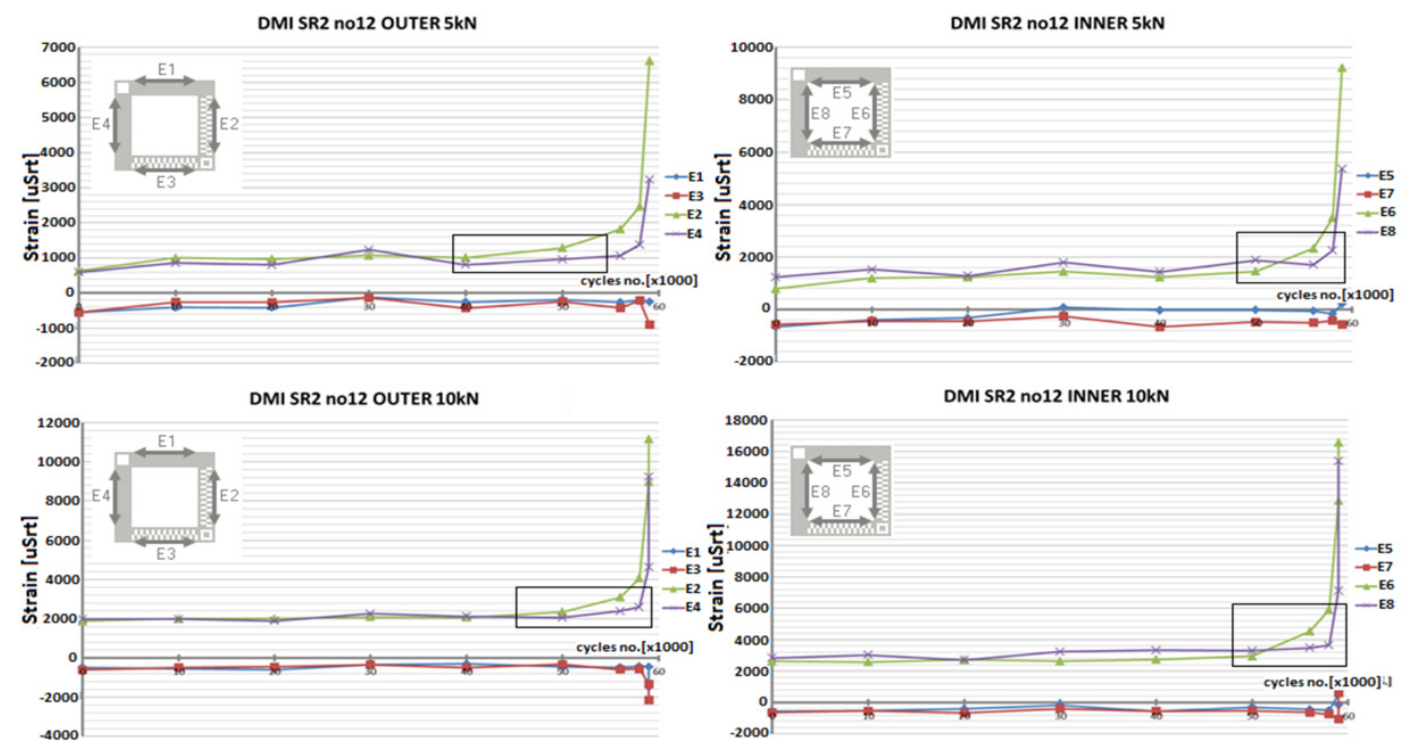

Figure 5. Test results for a flat specimen with a riveted joint under $5 \mathrm{kN}$ and $10 \mathrm{kN}$ axial load 
Test results are quite promising for both types of specimens. At the first stage of the test, strain values for opposing edges of the polymer gage are similar. Black rectangles in the charts mark the initial state in which the gages sense any anomalies around the fastener hole. A difference between stain values grows because of a crack developing only on one side of the hole. The inner edges of the gage respond faster than the outer ones due to a closer location to the hole. This fact confirms the possibility of detecting fatigue fractures in the structure and determining their direction. On the other hand, accuracy and stability of data increase as the load applied to the specimen grows.

\section{CRACK DETECTION USING RESISTIVE LADDER SENSOR}

Preliminary studies of electrical resistive ladder sensors were also conducted. The sensor's structure is similar to that of foil strain gauges. Differences in shape of the measuring grid, designed as a parallel connection of thin conductive paths, can be noticed. The method of integrating the sensor with the structure is identical to the one used for foil strain gauges.

When a crack opens under the sensor, a local deformation occurs and the foil with the paths is gradually torn apart. This progressively stops electric conduction. The signal from the sensor changes in accordance to Ohm's Law. This way, by fitting such a sensitive element in a location suspected of surface cracks and measuring its resistance, the possibility to detect and quantify fatigue fracture arises. In the investigation, two sensor types were compared.
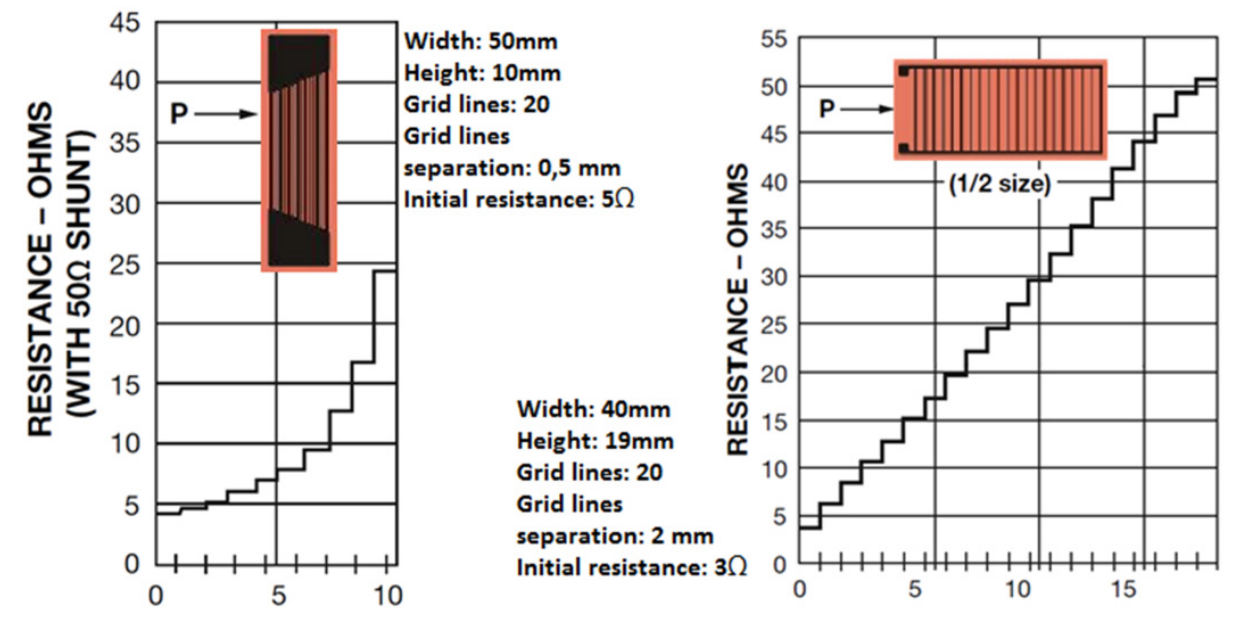

Figure 6. Resistance characteristics of two types of resistive ladder sensor

To be able to perform measurements with the resistive ladder sensors, it was essential to develop a special electronic circuit. As a data recorder, an appropriate 16-bit A/D converter card was used, connected to a PC computer.

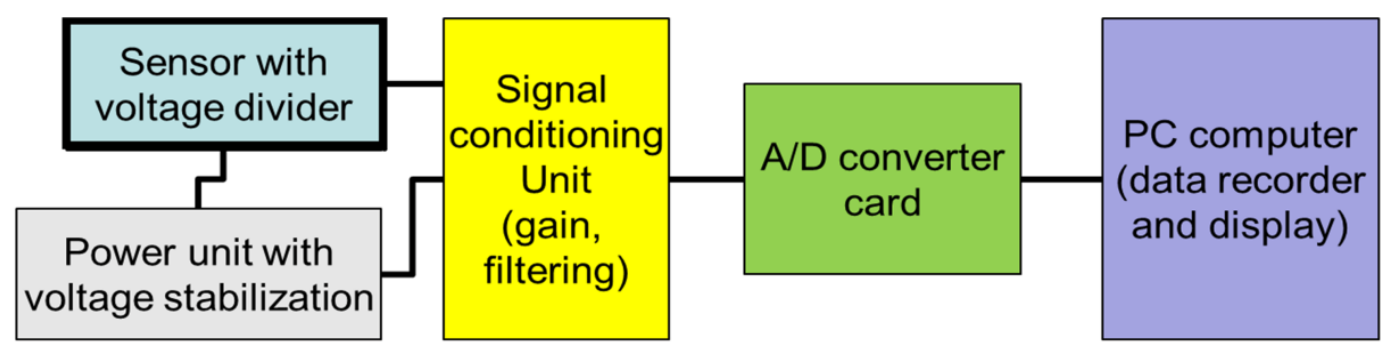

Figure 7. Resistive „ladder” sensor measurement system components 


\subsection{The conduct of testing and test results}

Preliminary tests were conducted on flat rectangular specimens with little notches on one edge using a fatigue test system. Specimens were made of PA7 aluminum, with dimensions H160xW50xT2 mm. The applied axial load was in the range of 7-12 kN, at the frequency of 10 $\mathrm{Hz}$. The results were depicted in the graphs, separately for both types of ladder sensors (A and B), for two test runs.
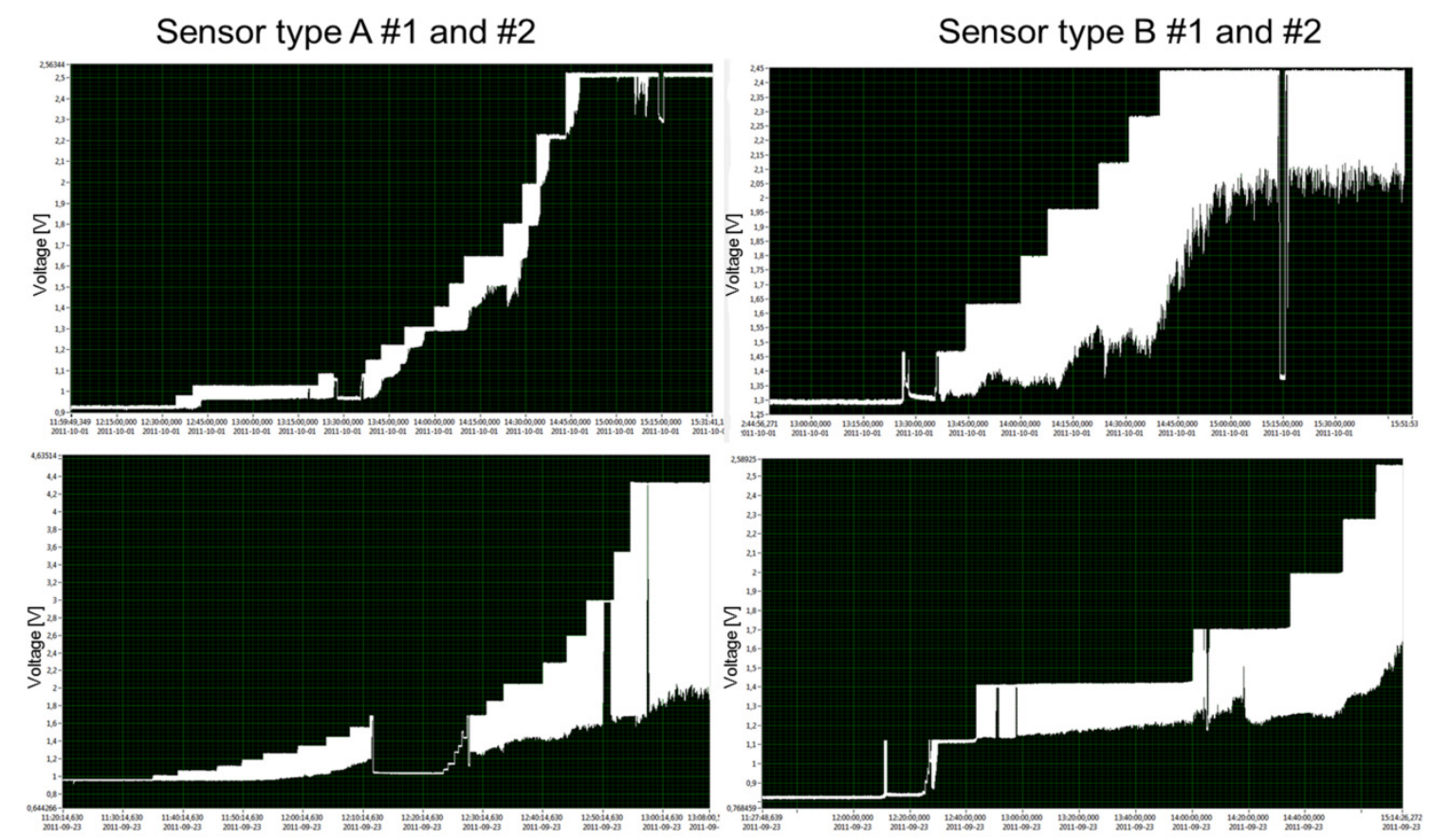

Figure 8. Test results for type A and type B ladder sensor for two identical specimens

Test results confirmed that it is possible to detect and quantify fatigue cracks with both types of ladder sensors. Some modifications in the signal conditioning unit are required, especially in gain and filtering, to increase voltage resolution and range, as well as to purify measurements from unwanted peaks and valleys. Stability and sensitivity of the sensor was satisfactory and the method is suitable for real-time measurements.

\section{CONCLUSIONS}

In this work, preliminary bench verification of two crack detection methods was performed. Both methods are capable of detecting fatigue cracks in the structure, although their principles of operation differ substantially. Further experiments are essential to confirm repeatability, reliability and accuracy of measurements on more complex structure areas.

Along with the collected data, the present preliminary verification study provided some practical knowledge not only about potential future applications and types of measuring approaches (in-situ or real time), but also about labor intensity of data post-processing as well as the field of fracture detection. Table 1 summarizes these observations and compares the two presented crack detection solutions. 
Table 1. Comparison of presented crack detection solutions

\begin{tabular}{|l|l|l|}
\hline \multicolumn{2}{|c|}{ Optical polymer gage solution } & \multicolumn{1}{c|}{ Resistive ladder solution } \\
\hline 1. & permanently integrated with the structure & permanently integrated with the structure \\
\hline 2. & no wires, no power supply to the sensor & needs additional wires for data and power \\
\hline 3. & no additional measurement circuit & needs signal conditioning and A/D converter \\
\hline 4. & operator is needed for measurements & no operator is needed for measurements \\
\hline 5. & access to a gage is essential & access only during installation \\
\hline 6. & in-situ, off-line measurements & real-time, on-line measurements \\
\hline 7. & need for baseline measure & no need for baseline measure \\
\hline 8. & detects cracks and fatigue plastic strain & detects crack and quantifies its length \\
\hline 9. & detection in the area near to the sensor & detection of cracks under sensor \\
\hline 10. & labour-consuming post-processing & easy post-processing \\
\hline 11. & $\begin{array}{l}\text { Accuracy depends on the operator's } \\
\text { experience }\end{array}$ & $\begin{array}{l}\text { accuracy depends on excitation voltage } \\
\text { stability and electronic circuit quality }\end{array}$ \\
\hline
\end{tabular}

\section{REFERENCES}

[1] Maley S., Plets J., Phan N. D. (2007). US Navy Roadmap to Structural Health and Usage Monitoring - The Present and Future. In American Helicopter Society $63^{\text {rd }}$ Annual Forum, May 1-3, Virginia Beach, VA.

[2] Uhl, T. „Współczesne metody monitorowania $i$ diagnozowania konstrukcji”, Wydział Inżynierii Mechanicznej i Robotyki Akademia Górniczo-Hutnicza, at the website http://fundacjarozwojunauki.pl/res/Tom2/6_Uhl.pdf

[3] Ranson, W.F. \& Vachon, R.I. Crack Detection and Growth Monitoring in Holes Using DMI SR-2 Technology. SEM Annual Conference 2007.

[4] Direct Measurements, Inc. ,SR-2 Operating manual”, June 2, 2008.

[5] Hild, F. (2006). Measuring stress intensity factors with a camera: integrated digital image correlation (I-DIC). Comptes Rendus Mechanique, 334(1), p. 8-12

[6] Bartelds, G. (1997). Aircraft structural health monitoring, prospects for smart solutions from a european viewpoint. In International Workshop on Structural Health Monitring, Stanford University, (USA), September 18 to 20, 1997.

[7] Speckmann, H. \& Henrich R. (2004). Structural health monitoring (SHM) - overview on technologies under development. Proc. of the World Conference on NDT, Montreal, Canada. http://www.ndt.net/article/wcndt2004/pdf/aerospace/ 563_henrich.pdf

[8] Vishay Micro-Measurement, „Special Purpose Sensors - Crack Propagation Patterns”, Document no. 11521, 9 May 2003.

[9] Crossbow Technology, Inc., ēKo Pro Series Data Sheet. San Jose, California, 2009.

[10] Klimaszewski, S. \& Dragan, K. (2010). Realizacja zadań związanych z Etapem II - Badania Doświadczalne Projektu Badawczego Własnego pt: Opracowanie koncepcji systemu monitorowania stanu technicznego łopat wirników nośnych śmigłowców z wykorzystaniem metod NDT i SHM. Wykonanie badań metodami SHM i NDT - ETAP II. Analiza uzyskanych wyników z badań. Opracowanie finalnego sprawozdania z badań", ITWL: Warszawa. (Sprawozdanie Nr 126/31/2010). 